\title{
HOW SHOULD AN ELECTRIC VEHICLE SOUND? USER AND EXPERT PERCEPTION
}

\author{
Jean-François Petiot* \\ Ecole Centrale de Nantes \\ Nantes, France \\ Jean-Francois.Petiot \\ @irccyn.ec-nantes.fr
}

\author{
Bjørn G. Kristensen \\ Technical University of Denmark \\ Lyngby, Denmark \\ bonkrist@gmail.com
}

\author{
Anja M. Maier \\ Technical University of Denmark \\ Lyngby, Denmark \\ anja.maier@cantab.net
}

\begin{abstract}
As electric vehicles are moving in on the automobile market, safety relating to acoustic perception is an important issue. It is a growing concern, particularly with respect to pedestrians, cyclists or visually impaired people. This can be addressed by adding sounds to the vehicle whilst at low speed. However, adding artificial sounds to an electric vehicle begs the question as to what kind of sound is appropriate. Appropriateness concerns technical specifications and is also linked to affective reactions of recipients of such a sound. Emotional reactions to 17 artificial exterior sounds for electric vehicles were investigated in an experimental setting with a total of 40 participants, 34 novice users and six sound experts.

Word association was used to elicit emotional reactions to the different sounds. Novice users employ more characterrelated terms to describe the sounds, while experts use more composition-based words. Analysis of variance and conjoint analysis was used to analyze participants' assessments of sounds according to two semantic scales (pleasantness and appropriateness). Considerable inter-individual differences in the ratings of pleasantness and appropriateness indicate a great diversity of opinion about the sounds. Novice users indicate their preference for the sound of the traditional combustion engine as a possible proposition. Whilst participants saw the necessity, there was generally little enthusiasm for adding sounds to electric vehicles. The contribution of the paper concerns the methodology to analyze the results of the experiment and implications for the design of sounds for electric vehicles.
\end{abstract}

\section{INTRODUCTION}

Electric vehicles (EVs) and hybrid vehicles are becoming a serious alternative to internal combustion engine cars [1]. However, due to reduced audibility, hybrid electric vehicles have a documented twice as high incident rate than cars with an internal combustion engine [2], and as Don Norman writes: "[q]uiet is good; silence may not be" [3]. At low speed (under $50 \mathrm{~km} / \mathrm{h}$ ) in particular, the wind and tyre/road interaction noises are not sufficient to signify the presence of an EV to road users, such as pedestrians, cyclists, or visually impaired people [4]. Regulation concerning the sounds of electric cars is still under study. Yet, several countries such as Japan and the United States of America already decided that adding artificial sounds to EVs is compulsory [5]. Whilst research has been conducted to recommend design guidance for warning sounds and external sound generation systems [6], design guidance for adding artificial exterior sounds to electric cars is still nascent.

The sonification of EVs is a complex design problem, with many constraints and stakeholders involved. Stakeholders include cyclists and pedestrians some of whom might have difficulties hearing warning sounds at low speeds, drivers who expect audio-feedback on the performance of the car, and other third parties who prefer not to be disturbed by additional sounds.

Having said this, safety is not the only goal for the design of sounds. Sounds provide opportunities for car manufacturers to brand their product through a sound signature and find loyal markets [7]. In that way, a sound may be conceptualized as a means of communication between the designer and end-users [8-9]. In the car interior, for example, the driver can infer the relative performance of the powertrain and have a better awareness of the speed of the car. Exterior sounds communicate the presence, proximity and speed of the car to other people in traffic.

Against this background, what kind of artificial exterior sound is appropriate? A sound that addresses safety concerns, informs about speed, is pleasant or at least not disturbing, and evokes the intended reaction from the users? In order to achieve 
this, we need to firstly understand what affective reactions sounds evoke in novice users and how this might differ from how sound experts perceive sounds. This paper addresses this issue directly by reporting an experimental study eliciting how users and experts perceive synthesized external sounds, what they expect the sound to be like and what their concerns might be. Therefore, the main research questions of this paper read as follows:

- $\quad$ Research Question 1 (RQ1):

Should there be added sound for EVs?

- Research Question 2 (RQ2):

What should an EV sound like?

- $\quad$ Research Question 3 (RQ3):

How do users and sound experts perceive EV sounds?

The experiment included an open word association task as well as a rating task on a bipolar semantic scale to assess a set of different sounds with respect to appropriateness and pleasantness. The sounds used in this study are synthesized sounds designed for exterior loudspeakers simulating car sounds as they may be perceived, e.g. by pedestrians. The overall objective of this study is to support the sound designer in identifying a clear goal for the design of an appropriate and pleasant exterior sound for hybrid and electric vehicles such as an electric car.

The remainder of the paper is organized as follows. The next section discusses extant studies in literature by integrating literature from product experience, design communication, and psychoacoustics. Next, the experiment is described. It starts with a presentation of the set of sounds used, the tasks given to the participants, and the method used for the analysis of the results. Then, results from both the qualitative and quantitative analyses are presented. The concluding section provides implications for design research and design practice.

\section{PRODUCT SOUND EXPERIENCE}

We purchase products both for what the product does for us, for the 'product functions', and also for how the product makes us feel, for what one might call 'product emotions' [10]. We experience products through our senses, e.g. through seeing, touching, tasting, smelling, and hearing. Each interaction with the product is a touch point influencing our reasoning, emotional state, purchasing decision, preference, and expectations with respect to the product [11]. In that way, a product makes sense for us, we attribute meaning to the product. We might find a sports car powerful, fast, and feel excited when looking at it or driving it. We might associate comfort and the feeling of being at home with a family car.

When driving a car, our product experience is influenced by a number of stimuli such as visual appearance or tactile sensation. In addition, sound is an important part of the driving experience [12]. This includes internal sounds in a vehicle to provide auditory feedback, for example, on whether the engine is running ensuring and increasing the driver confidence that everything is working normally. It also includes external sounds when locking the car or alarm sounds when someone is trying to break into the car. Specific sounds have to be integrated into the whole soundscape. In the driving context, listening to the radio adds sound to the already present noises from the road and tires. Other passengers, conversations, mobile phone conversations can each add distraction. There may easily be an overabundance of sounds, quickly leading to a too high cognitive load for the user of a car and to 'audio fatigue'.

Product Sound Design (PSD) is an emerging and important topic within product development [13]. Sound has an immediate, direct link to both the rational and emotional parts of our brain and can trigger vivid recollections of past experiences, helping us remember intricate details associated with events [12]. The sense of hearing also allows for speech perception and understanding, which in turn forms the basis of our ability to communicate with others [14].

In our daily life, we are confronted with the sounds of industrial products. Physical products have both consequential sounds that are the result of moving parts, airflow etc. and intentional sounds that are added or altered to enhance the experience of the product [15]. Consequential sounds refer to the sounds that are electrically or manually produced as a consequence of a function, e.g. a hairdryer producing engine sounds when turned on. Intentional sounds are sounds that are deliberately designed and added to a product by designers, many of which are digitally synthesized sounds [13]. For example, cars producing a warning beep when the seat belt is not fastened whilst the car is in driving mode. In this study, we are concerned with intentionally created sounds for EVs.

Car companies are developing sounds for electric cars. Experts at Jaguar Range Rover, for example, have conducted an initial study to develop appropriate warning sounds for a luxury vehicle using an exterior sound simulator [1]. Engineers at Nissan have developed an Approaching Vehicle Sound for Pedestrians (VSP), providing auditory cues when driving at low speed forward or when reversing. Sound with modulation or rhythmic structure stands out in ambient noise more than sound without modulation [5]. The car industry developed objective metrics used for the design of different sub-systems in a vehicle such as air conditioning, the engine, and horns [16-17]. These psychoacoustic metrics for the acoustics of cars are also relevant for electric vehicles, in particular for the road and wind noise contribution [18].

In addition to technical specifications such as a mapping between the sound and the state it is meant to represent, to design appropriate and pleasant sounds, designers need to understand how users experience product sounds. Despite proposals from car-makers concerning the sonification of EVs, few studies are concerned with the perception of these sounds by users [4]. Most of the times, people use those auditory 'cues' unconsciously [15]. How do we then elicit users' perceptions?

Whilst designers and design researchers have studied underlying processes of product semantics such as on product form perception [11] [19] [20], product sound perception is still nascent. Previous studies on the perceived qualities of different sounds have, for instance, been measured by the use of Kansei words [21-22]. These were word pairs such as hard-soft, dull- 
clear, silent-noisy. A similar approach was made based on a preselected number of sound-characterizing words [23]. Semantic associations of synthesized sounds such as warning signals have been elicited [24], focusing on acoustic parameters. Recent work examined the basic semantics of consequential product sounds to explain meaningful associations of the auditory property of products [13].

With respect to users' preferences towards external vehicle sounds, in their study with a panel of 380 people, Wogalter et al. [25] identify the 'traditional engine' as the predominant response to what type of sound is most appropriate. Similarly, Nyeste et al. [26] conducted a preference study on a set of potential sounds for EVs with the semantic differential method and showed that the 'traditional sound' of a combustion engine is the most acceptable.

There have been studies on novices and expert designers on how they approach design tasks [27], yet, an assessment of the emotional reaction to or psychoacoustic experience with intentional product sound for the exterior of electric vehicles is still under-explored. We argue here that the distinction between novices and expert users is important in that it allows us to elicit design criteria both for pleasant and also for technically appropriate sounds for electric vehicles.

\section{MATERIALS AND METHODS}

For the purpose of exploring the perception of sounds for EVs, we carried out an experiment with a set of 17 sounds and in total 40 participants between 21 and 67 years of age (average age of ca. 35), all of whom reported normal hearing. Two groups of subjects were considered:

- a group of novice users (denoted 'novices' as they have no particular expertise in acoustics and sound design). They constitute the User group (number of subjects $\mathrm{N}_{\mathrm{u}}=34$ ), and

- a group of experts in sound design (professional sound designers and acoustics experts). They constitute the Expert group (number of subjects $\mathrm{N}_{\mathrm{e}}=6$ ).

As we are aware of the imbalance of the amount of participants in each group, the use of statistics to generalize the conclusions would be doubtful. Nevertheless, we consider the descriptive analysis of the results as interesting in that it uncovers differences between the groups.

\subsection{Description of the sound design}

In total, 17 different experimental sounds were created for this study by the first author. The sounds were synthesized using the mathematical modeling software Matlab and the additive synthesis technique. In order to generate different but plausible sounds for an electric car, after an analysis of current sounds of different carmakers [4] and personal propositions, four main components of the sound were considered. The components are also named design factors in this paper.

- Component C1 'A thermic Motor Sound'.

This component synthesizes the first harmonics of a classical 4-stroke internal combustion engine (H0.5, H1, $\mathrm{H} 1.5, \mathrm{H} 2, \mathrm{H} 4, \mathrm{H} 6$ ).

- Component C2 'A Harmonic Sound'.

This component synthesizes different musical 'notes' that constitute a chord (chord with 2, 3, or 4 notes),

- Component C3 'A Noise Sound'.

This component synthesizes a filtered noise,

- Component C4: 'Amplitude Modulation'.

This last component is an amplitude modulation of the first three components that may create more complexity and small 'temporal events' in the sound.

The final sound is the sum of these four components. 17 different sounds were designed. Their composition according to the different components (C1 motor: yes/no - $\mathrm{C} 2$ musical chord: no/consonant/dissonant - $\mathrm{C} 3$ noise sound: broad/narrow - C4 modulation: yes/no) is given in Annex A.

Since it is out of the scope of this paper to describe all the parameters of the synthesizer (there are more than 70 independent parameters to define a sound), we can mention that all the frequencies and amplitudes of the components are adjustable, to create credible and very different sounds. This sound is not constant but 'played' by a control parameter of the car: the speed. To make the sound evolve with the speed of the car, we choose to adjust the frequencies and the amplitudes of the different components according to the speed.

To simulate the movement of the car for the tests, we defined a pattern of speed similar for all the sounds (duration $\mathrm{T}=18 \mathrm{~s}$ ). This included four phases of driving: idling, acceleration, constant speed (typically: $50 \mathrm{~km} / \mathrm{h}$ ), deceleration and idling (Figure 1).

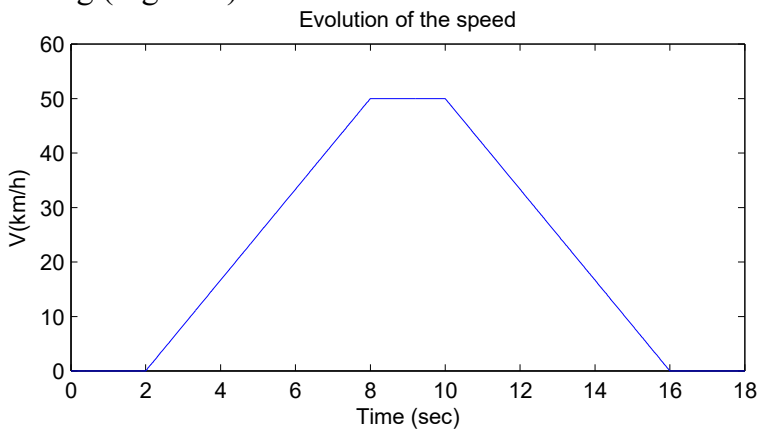

Figure 1: Speed pattern of cars for sound evaluation

Mapping the speed of the car with the parameters of the sound (frequencies and amplitudes of the components) makes the sounds evolve and 'simulates' the movement of the car. Analogous to an internal combustion engine, for this mapping, the rule used is that the frequencies of the components increase, when the speed increases. This pattern creates realistic conditions to facilitate the perception of speed, acceleration or deceleration.

An example of the spectrogram of the sound S15 is given in Figure 2. The sound is made of a broadband noise (50$1000 \mathrm{~Hz}$ ), the frequency range of which increases with the 
speed of the car. A modulation of the amplitude of the noise is added. The frequency of the modulation increases with the speed as seen in the vertical stripes on the spectrogram. For this sound, the design intent was to mimic a heartbeat when the car accelerates.

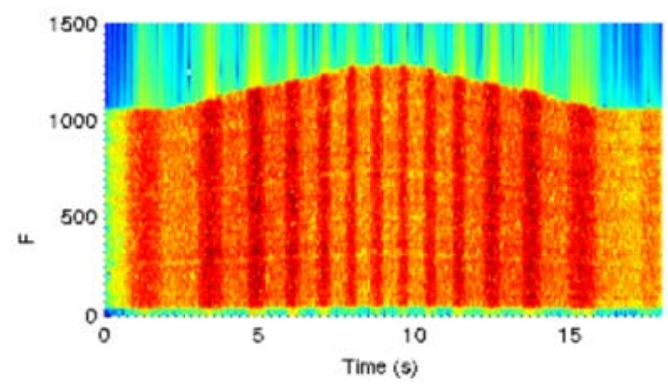

Figure 2. Spectrogram of Sound 15

\subsection{Description of the experiment}

The main objective of the experiment was to capture affective responses of 6 experts and 34 novice users on the 17 sounds designed for potential addition to EVs.

There were three stages in the experiment. During the first stage, the respondents were informed of the purpose of the study (external sound of electric cars) and were asked to give information about their age, gender, occupation and hearing ability (normal or not). An open question was asked on: 'Should there be added sound for EVS?' (RQ 1).

In the second stage, respondents were given a headset and each of the 17 sounds stored on a computer was played once. After each sound, the respondents were asked to rate the sounds on semantic scales (quantitative test) and asked to describe the sound using adjectives (qualitative test) before continuing to the next sound. 'How do users and sound experts perceive EV sounds?' (RQ 3). During this stage, for the quantitative test, the participants were first asked to rate the sounds on an unstructured semantic scale according to the two following descriptors:

- Appropriateness: is the sound appropriate for an EV?

- Pleasantness: is the sound pleasant or not?

Then, for the qualitative test, the response was captured through words used by the respondents when describing their reactions to the sounds. To control for carry over effect, the order of sounds for the subjects followed a Williams Design [28]. Data was recorded and kept in a file to enable subsequent coding.

During the third stage, once all sounds were listened to, a final open question concluded the experiment: 'What should an EV sound like?' (RQ 2).

\subsection{Qualitative analysis using word association}

Word association or semantic association is a method that is commonly used in consumer research [29-30-31], for example, to uncover the image of a brand in the mind of the consumer or the attributes that they associate with a particular product. It is assumed that the first associations or beliefs that consumers have about a product are those that are most closely linked to their behavior toward that product [32]. In this study, we employed the method to elicit first affective reactions from users to sound. Yet, because we did not have a defined set of semantic descriptors for intentional product sounds, we followed an explorative approach [33], allowing participants to choose their own words.

Having elicited how users describe the sounds, we analyzed the transcripts for each sound from the participants in order to find categories. The method used to analyze the transcripts was inspired by a grounded theory approach [34]. This approach is used by other researchers with similar goals of identifying key themes or for describing moderating influences on the design as communication process between designers and consumers [8].

Six categories emerged from the raw data that are described as: 'negative feeling', 'positive feeling', 'motionrelated', 'comparative', 'composition-based', and 'characterrelated' (see Table 1). Adjectives were only grouped under one category. One may argue, however, that the adjectives in the negative -and positive connotation- categories could also be grouped under the character-related category. Categories indicate the kind of reaction that the sounds evoke in a person.

\section{Table 1. Categories and examples of words used by} participants when describing the sounds

\begin{tabular}{|c|c|c|}
\hline Category & Description & Examples \\
\hline $\begin{array}{l}\text { Negative } \\
\text { feeling }\end{array}$ & $\begin{array}{c}\text { Adjectives referring to a negative } \\
\text { connotation or negatively } \\
\text { perceived quality of a sound }\end{array}$ & $\begin{array}{l}\text { 'bad', } \\
\text { 'bothersome', } \\
\text { 'poor' }\end{array}$ \\
\hline $\begin{array}{l}\text { Positive } \\
\text { feeling }\end{array}$ & $\begin{array}{c}\text { Adjectives referring to a positive } \\
\text { connotation or positively } \\
\text { perceived quality of a sound }\end{array}$ & $\begin{array}{c}\text { 'good', } \\
\text { 'pleasant', } \\
\text { 'comforting', }\end{array}$ \\
\hline $\begin{array}{l}\text { Motion- } \\
\text { related }\end{array}$ & $\begin{array}{l}\text { Adjectives referring to a type of } \\
\text { motion that the sound indicates }\end{array}$ & $\begin{array}{l}\text { 'flapping', } \\
\text { 'accelerating', } \\
\text { 'bouncing' }\end{array}$ \\
\hline Comparative & $\begin{array}{l}\text { Adjectives referring to the sound } \\
\text { of something (else) which the } \\
\text { respondent may be familiar with }\end{array}$ & $\begin{array}{l}\text { 'ghostly', } \\
\text { 'carlike', } \\
\text { 'SCIFI' }\end{array}$ \\
\hline $\begin{array}{l}\text { Composition- } \\
\text { based }\end{array}$ & $\begin{array}{l}\text { Adjectives referring to the } \\
\text { composition of a sound in terms } \\
\text { of technical aspects, musicology } \\
\text { terms, or structure (e.g. chords, } \\
\text { modulation, noise, pitch) }\end{array}$ & $\begin{array}{l}\text { 'booming', } \\
\text { 'harmonious', } \\
\text { 'high-pitched' }\end{array}$ \\
\hline $\begin{array}{l}\text { Character- } \\
\text { related }\end{array}$ & $\begin{array}{l}\text { Adjectives referring to the } \\
\text { perceived character of the sound }\end{array}$ & $\begin{array}{l}\text { 'calm', } \\
\text { 'sporty', } \\
\text { 'intrusive', }\end{array}$ \\
\hline
\end{tabular}

\subsection{Analysis procedure of quantitative data}

We used consonance analysis to study the agreement between the subjects in their ratings of Pleasantness and Appropriateness. This method, described in [35], is based on a principal component analysis (PCA) of the matrix of the individual ratings of the sounds $Y$ (sounds $\times$ subjects $)$. In this PCA, the individuals are the sounds and the variables are the subjects. A high consensus leads to a high percentage of variance on the first principal component. The analysis was 
made separately for Pleasantness (matrix Y1) and Appropriateness (matrix Y2).

To confirm the results concerning agreement and to study the differences between the sounds, a two-way Analysis of variance (ANOVA) with interaction of the ratings of Pleasantness and Appropriateness was made with the factor 'assessor' and the factor 'sound'.

The relationship between subjects' perceptions and the four components of the sound, also termed design factors here, has been investigated with conjoint analysis [36]. This approach, known in Kansei Engineering as the 'quantification theory type I' [37], proposes to model a quantitative response by qualitative factors, with different levels. A simple additive model is generally proposed for capturing the quantitative response (Eqn. 1):

$$
\hat{y}_{i}=\mu+\sum_{j=1}^{f} \sum_{k=1}^{k_{j}} a_{j k} \cdot \delta_{i}(j k)
$$

With: $\hat{y}_{i}$ : response for product $i$, provided by the model

$f:$ number of factors

$k_{j}$ : number of levels of factor $j$

$a_{j k}$ : part-worth utility for the level $k$ of factor $j$

$\delta_{i}(j k)$ : dummy variable. $\delta_{i}(j k)=1$ if the level of factor $j$

in product $i$ is $k$, zero otherwise

$\mu$ : intercept

Thus, if there are $f$ factors with $k_{j}$ levels, we must estimate $p=1+\sum_{j=1}^{f}\left(k_{j}-1\right)$ parameters. The estimates of the part-worth are obtained with an Ordinary Least Square procedure (ANOVA). We used ANOVA in our application to explain the quantitative ratings according to pleasantness and appropriateness by the 4 design factors $\mathrm{C} 1 \mathrm{C} 2 \mathrm{C} 3 \mathrm{C} 4$ that describe the sounds: C1 (2 levels: yes/no), C2 (3 levels: none/consonant/dissonant), C3 (2 levels: broad/narrow), C4 (2 levels: yes/no) (see Annex A). Before fitting the ANOVA model, we have to verify the efficiency of the experimental design given in Annex A. Let $\mathrm{X}$ be the matrix of the experimental design (orthogonal coding), $\mathrm{N}_{\mathrm{D}}$ the number of designs, $p$ the number of parameters to estimate in the model. The $D_{\text {efficiency }}(\%)$ of a design [38] is given by Eqn. 2 :

$$
D_{\text {efficiency }}=100 \cdot \frac{1}{N_{D}\left|\left(X^{t} X\right)^{-1}\right|^{1 / p}}
$$

The $D_{\text {efficiency }}(\%)$ of the experimental design presented in Annex $\mathrm{A}$ is $80 \%$. Even if this design is not balanced and not orthogonal, this efficiency is considered as sufficient to estimate the part-worth utilities of the factor levels.

\section{RESULTS OF THE QUALITATIVE ANALYSIS ${ }^{1}$}

\subsection{Should there be added sound for EVs? (RQ1)}

Generally speaking, the answers to the question as to whether there should be added sound for EVs were fairly mixed. There were four typical answers; 'I think it is a silly/bad idea', 'It will be a nuisance', 'I think it is a good idea', 'It is necessary for safety', and 'I have no opinion'. Table 2 gives the proportions of users' and experts' opinions.

Table 2. Opinions on adding sounds to EVs

\begin{tabular}{ccc|cc}
\hline $\begin{array}{c}\text { Users } \\
\text { for }\end{array}$ & $\begin{array}{c}\text { Users } \\
\text { against }\end{array}$ & $\begin{array}{c}\text { Users no } \\
\text { opinion }\end{array}$ & $\begin{array}{c}\text { Experts } \\
\text { for }\end{array}$ & $\begin{array}{c}\text { Experts } \\
\text { against }\end{array}$ \\
\hline $57 \%$ & $23 \%$ & $20 \%$ & $67 \%$ & $33 \%$ \\
\hline
\end{tabular}

In sum, our results show that most of the users in the experiment are in favor of adding sounds to electric cars and see the necessity. However, there was generally little enthusiasm for this hypothetical question, because the added sound was considered as a necessity rather than an opportunity.

The sound experts were mostly in favor of adding sounds to electric cars. Four said it was a good idea to add some kind of sound. One said he had mixed feelings and could see the purpose of adding sounds but would rather be without it as it would be a nuisance. Another said that it was not necessary for him and had difficulty imagining a credible sound for such a purpose.

Given that adding sound is compulsory, this little enthusiasm from the users and expert sound designers indicates that the designer will have to convince users of the relevance of the sound, for example by giving an added value to the sound, to reinforce the brand image of the car, or by designing an unobtrusive, but efficient sound.

\subsection{What should an electric vehicle sound like? (RQ2)}

The most dominant answer from users was that an electric car should sound 'like a regular car' and resemble a combustion engine sound. This result is in accordance with previous studies on the subject [25-26]. Already in third place, we find that users prefer 'no sound' (see Figure 3).

Sound experts gave varied but also complementary answers to this question. Examples are that there should be an 'electric motor association', with 'frequency varying with speed', light gearing emulation', and a sound 'not too rough', and 'modulation not too rough.' Their answers were generally design-oriented. They reported design directions and propositions for innovations for the composition of the sound, including frequency varying with speed, organic, and contrapuntal.

\footnotetext{
${ }^{1}$ Note that among the $\mathrm{N}_{\mathrm{u}}=34$ users, only 29 described the sounds with words.
} 
Users: What should an electric vehicle sound like? $\left(\mathrm{N}_{\mathrm{u}}=29\right)$

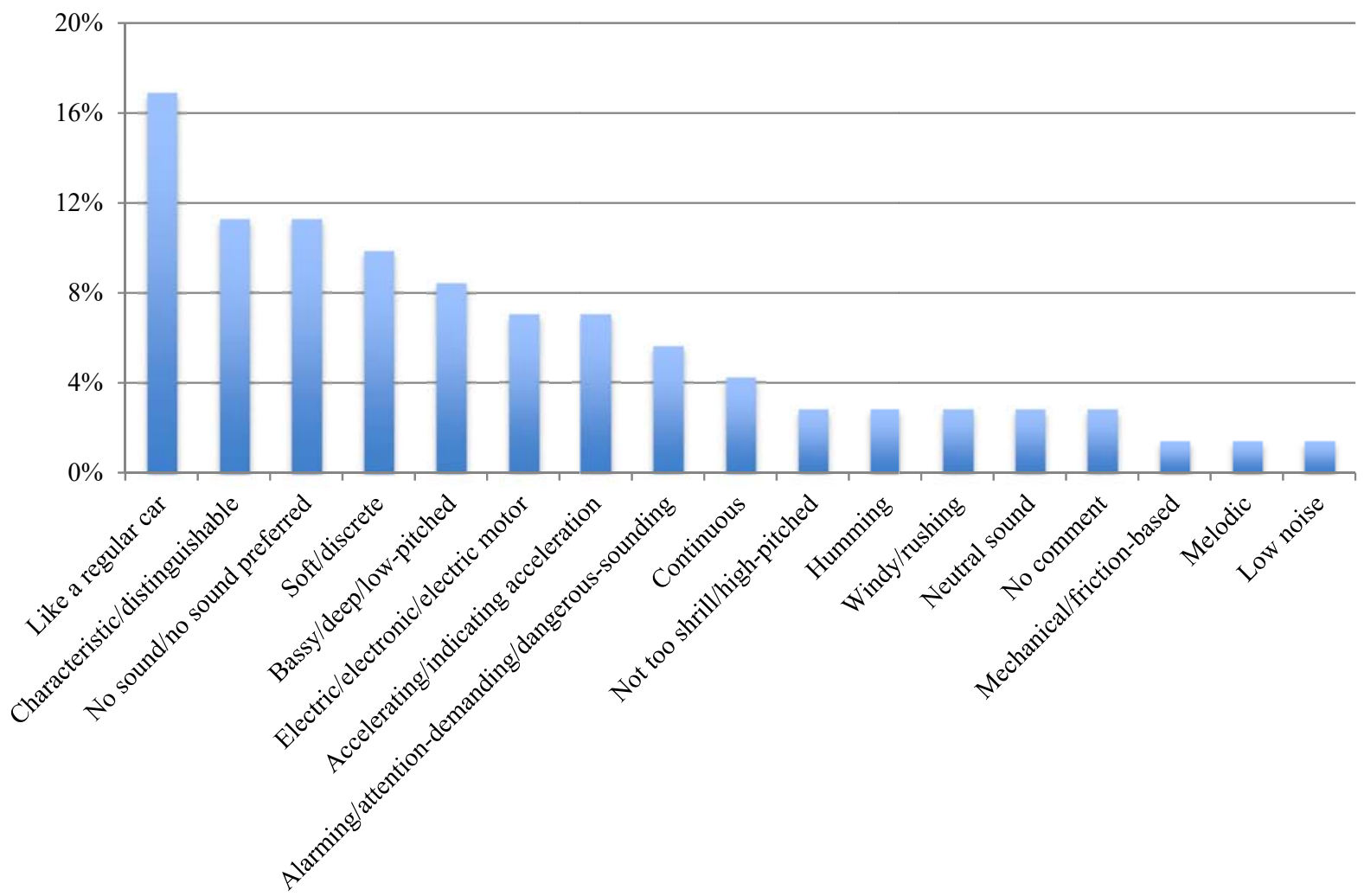

Figure 3. Opinions on what an exterior sound of an EV should sound like

\subsection{Comparison of how users and experts perceived the 17 sounds (RQ3)}

This comparison is made by reporting the words that were generated most often, the proportion of words in each category, and words used to judge the positive and negative qualities of the sounds as generated by both groups.

\subsubsection{Most occurring words associated with the sounds}

The five most occurring terms, for all the 17 sounds, can be seen in Table 3 .

The users employed predominantly non-technical vocabulary and focused more on comparative and characterrelated formulations. This is also common when people describe sounds: people use mainly images and metaphors. The majority of words used link the sounds heard to the sound of a source that the novice users knew, e.g. 'siren-like', or they would use a word that referred to character traits such as 'scary'. The large occurrence of the words 'annoying' and 'pleasant' shows that pleasantness is an important part of the evaluation from users. These results are in agreement with findings from sensory analysis: novice subjects express first their preferences (like/dislike).
The sound experts used many of the same words as the group of novice users. But we see a difference in that experts used considerably more technical terms. The five most occurring adjectives from experts are given in Table 3. Except 'annoying', the other four adjectives are in the 'compositionbased' category. A very high number of occurrences in the 'composition-based' category suggest that the sound experts express themselves in a slightly different way than users about sounds. Due to their knowledge, experts use more adjectives describing the composition of the sounds.

Table 3. The most occurring adjectives from users and experts

\begin{tabular}{ll|ll}
\hline \multicolumn{3}{c}{ Users $\left(\mathbf{N}_{\mathbf{u} 1}=\mathbf{2 9}\right)$} & \multicolumn{1}{c}{ Experts $\left(\mathbf{N}_{\mathbf{e}}=\mathbf{6}\right)$} \\
\hline $\begin{array}{l}\text { Occurrence in } \\
\text { experiment }\end{array}$ & Adjective & $\begin{array}{l}\text { Occurrence in } \\
\text { experiment }\end{array}$ \\
\hline Annoying & 80 & Deep & 17 \\
\hline Pleasant & 36 & Futuristic & 14 \\
\hline $\begin{array}{l}\text { Helicopter- } \\
\text { like }\end{array}$ & 35 & Annoying & 13 \\
\hline Futuristic & 35 & High-pitched & 12 \\
\hline Windy & 29 & Noisy & 10 \\
\hline
\end{tabular}




\subsubsection{Comparison of the profiles of categories}

All adjectives proposed by the users and the experts were coded in categories, presented in the previous section. To estimate the weight of each category, the total number of adjectives in each category was computed for both groups. The relative weight as percentages of occurrence of each category for each group is plotted in Figure 4.

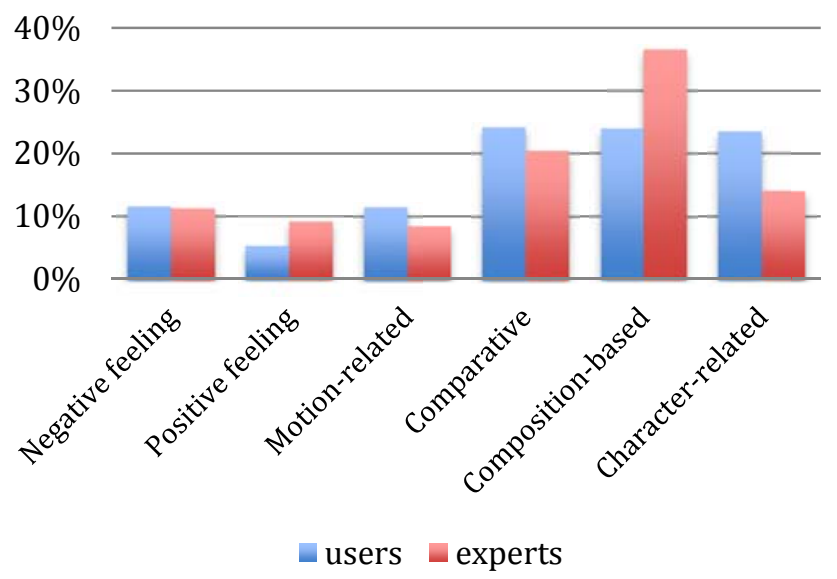
Figure 4. Comparison of the word association profile
for users and experts

Experts mainly used adjectives in the 'composition-based' category. The profile of the users is more flat, since they used very few 'positive feeling' terms. Concerning the comparison, the relative weight shows important differences between the groups for the categories 'composition-based' and 'characterrelated': experts use more 'composition-based' adjectives than users, and the users more 'character-related' words than experts. Due to their expertise, the experts are more focused on the technical aspects of the sounds. The users express more instinctively their feelings and the connotations of the sounds.

\subsubsection{Positive and negative qualities of sounds}

In addition to adjectives describing the sounds, subjects were asked to give characteristics of the sounds that they liked, or that they disliked (Table 4).

Table 4. Positive and negative characteristics of the sounds

\begin{tabular}{llll}
\hline & \multicolumn{2}{l}{ Users } & \multicolumn{2}{c}{ Experts } \\
\hline Positive & negative & positive & negative \\
\hline Electronic & High-pitched/ & Electric motor & Slow \\
Windy & sharp/shrill & Sounds without too & modulation of \\
Humming & Helicopter- & dominating low & noise \\
Low/deep/ & like/rotating & frequency & contribution \\
bassy & Beeping & Constant structure & Jet-motor \\
Accelerating & Windy/ & Simple & Out of context \\
Traditional & whistling & Low-frequency & sounds \\
Motor/car- & Tinnitus- & Musical major chord & Misplaced \\
like & like/airplane- & Futuristic/new & periodicity \\
Futuristic & like & Familiar & Varying speeds \\
Helicopter- & Deep/low- & Engine component & Snappish \\
like & frequency & Windy noise & Fast \\
\hline
\end{tabular}

\begin{tabular}{llll}
\hline Monotonous/ & Modulating & Disk wheel with organic & modulation \\
constant & High treble & element & High- \\
Scary/ & Gear sound & frequency \\
& alarming & Mix between different & Pink noise \\
Two-piece & speed curves & Noise \\
& & Attention demanding & Spaceship-like \\
& Fluctuating & sounds \\
& Unexpected/ & SCIFI \\
& atypical & Airplane-like \\
& Booming & sounds \\
& Straight & Vibrato/ \\
& Familiar and credible & tremolo \\
& Identity creating & \\
& &
\end{tabular}

For users, the most enjoyed type of sound was described as low/deep/bassy. Sounds that communicated acceleration were also among the most mentioned positive traits. The high $\mathrm{pitch} / \mathrm{sharp} / \mathrm{shrill}$ is a particular bad characteristic. But there are conflicting opinions in the propositions of the users, certain positive traits being also negative (low frequency, helicopterlike).

The answers from the experts are more diverse, since the sample size is smaller. They had specific opinions about the positive traits, but all considered the high pitch as an undesirable attribute. Further detailed analyses of the sounds are necessary to assess implications of the semantic associations evoked.

\section{RESULTS OF THE QUANTITATIVE EXPERIMENT}

\subsection{Agreement between the participants}

Agreement between the subjects in their ratings of Pleasantness and Appropriateness was studied by consonance analysis. For each descriptor and each group (users and experts), a standardized PCA of the matrix $Y$ (sounds $\times$ subjects) of the individual ratings was made. For the 34 users (P1 to P34) and the descriptor Pleasantness, the plane of the two first factors of PCA is illustrated in Figure 5.

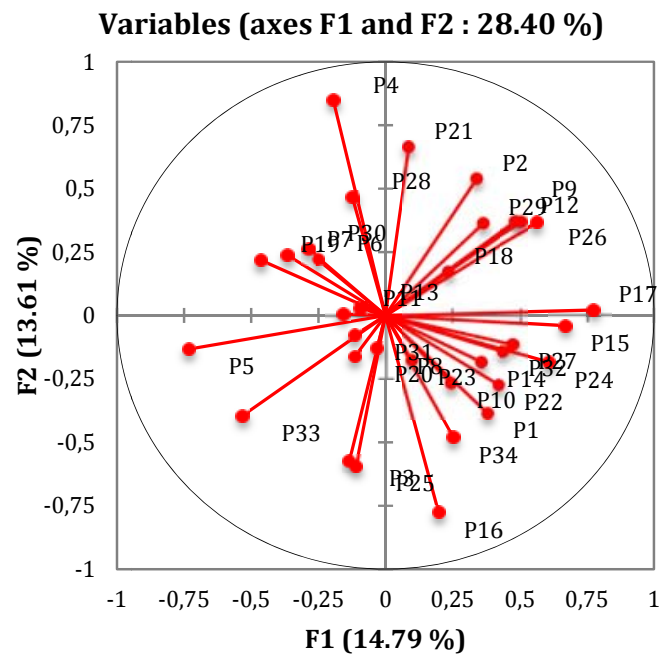

Figure 5. Consonance analysis (PCA) for the descriptor pleasantness (users) 
Results show that agreement between the subjects is very weak: the percentage of variance on the first two factors is low $(28.4 \%)$, which is a sign of a high dimensionality in the ratings. The results were similar for the descriptor Appropriateness and also for the group of experts. To confirm this high disagreement, a two-way Analysis of Variance with interaction (ANOVA) with the factors 'sound' and 'subject' for each descriptor and each group showed always a non-significant effect of the 'sound' factor ( $p$-value $>5 \%$ ), a significant effect of the 'subject' factor ( $\mathrm{p}$-value $<1 \%$ ), and a significant effect of the interaction sound*subject ( $\mathrm{p}$-value $<1 \%$ ). These results are a sign of a lack of consensus in the group of subjects. This lack of consensus is in fact rather natural, because of the subjective nature of the two descriptors, more related to the preferences and opinions of the subjects rather than to perceptual or sensory dimensions. This result is in accordance with general results in sensory analysis, which show important inter-individual differences according to hedonic measurements [39].

\subsection{Extreme sounds for each group}

Since disagreement between the subjects is considerable, the study of the most important differences between sounds showed that on average, the same pairs of sounds were extreme on the appropriateness and the pleasantness scales (significant differences between of the average value (t-test, $p$-value $<5 \%$ )). Figure 6 presents the position of the sounds according to the average value of the two descriptors for the user group. For users, the two extreme sounds are S6 (most pleasant and appropriate), with the opposite being S16.

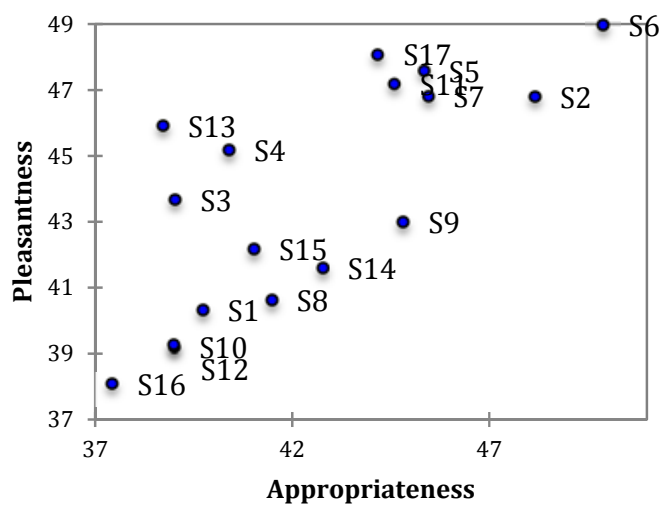
Figure 6. Average position of the sounds for the two
descriptors (users)

For experts, the two extreme sounds are S14 (most pleasant and appropriate), with the opposite being S4.

To explain the sounds positioned at opposite ends of the chart, it is interesting to come back to the descriptive words elicited by the subjects on these sounds during the qualitative part of the experiment. The cloud tags in Figure 7 illustrate a synthetic view of all descriptive words elicited from the subjects.
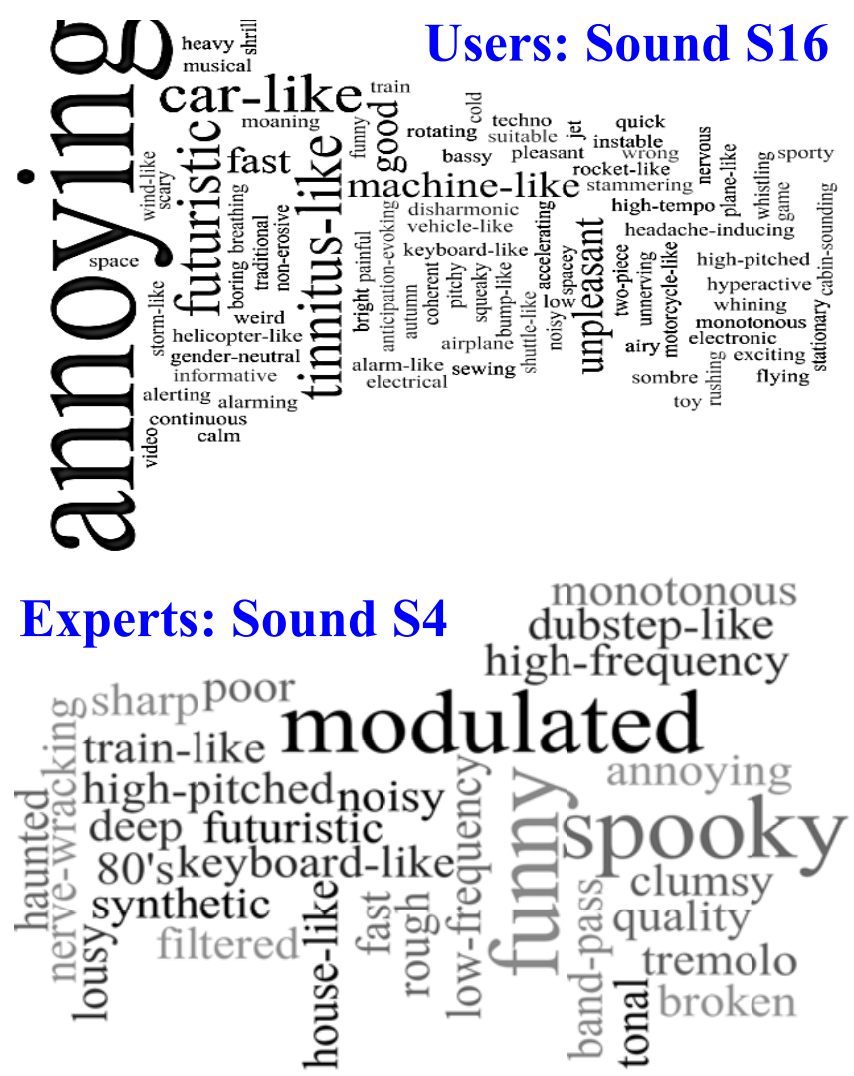

Figure 7. Cloud tags of descriptive words for the two least appropriate sounds (wordle.org)

The cloud tags are interesting in order to uncover positive and negative traits of the sounds and to give advice to the sound designer.

In describing users' judgment on the sound which received the lowest score in both appropriateness and pleasantness, novice users seem to attribute it to mechanical sounds as inferred by words used, such as 'alarming' and 'machine-like'. One of the most-often used terms is 'annoying'. From this one we might infer that the sound needs to blend in and not be specifically noticeable when not intended to.

In describing experts' judgment on the sound which received the lowest score in both appropriateness and pleasantness, experts describe sensory unpleasantness by referring to the sound as 'rough', 'broken', 'tremolo' (see lower word cloud in Figure 7), as also suggested by Zwicker and Fastl [40]. Further, inappropriateness seems to be explained by nonnatural qualities through words used such as 'synthetic', 'filtered', and 'monotonous'. Lastly, inappropriateness and unpleasantness may stem from a perceived threat that may be inferred from words used such as 'spooky' and 'haunted-houselike'.

Semantic attributes used to describe sounds elicited here reflect participants' preference and could be used by designers to evaluate the intended product character and expected product experience. Instead of merely asking for pleasant - unpleasant, 
designers could use more specific words such as 'annoying' or 'unnerving' with novice users or 'synthetic' or 'monotonous' with experts to qualify what unpleasant might mean.

\subsection{Relationship between quantitative assessments and design factors of the sounds}

We used conjoint analysis to explain the quantitative ratings according to pleasantness and appropriateness by the four design factors C1-C4 that describe the sounds. For the whole group of subjects (users or experts) and for the two descriptors pleasantness and appropriateness, results of the ANOVA model with four factors $(\mathrm{C} 1, \mathrm{C} 2, \mathrm{C} 3$, and $\mathrm{C} 4)$ show that none of these factors had a significant effect ( $p$-value $>5 \%$ ) on the response: the factors are unable to explain the differences between the ratings. This is not surprising, because of the considerable disagreement between the subjects in their ratings.

To explain the differences between the ratings of the sounds and to get more homogeneous subgroups, a partitioning of the group of subjects is necessary. Because of the small size of the experts group (6 individuals), we decided not to partition this group and focused our analysis on the group of users only. In order to provide a partition of the users and to define subgroups who are homogeneous in their ratings of the sounds, a hierarchical ascendant classification (HAC) was done on matrix $Y$ (sounds $\times$ subjects) for the descriptors pleasantness and appropriateness. In the HAC, we used Euclidian distance and Ward's criterion as the linkage rule. Three subgroups of users (G1, G2, G3 for pleasantness, G4, G5, G6 for appropriateness) were considered, according to the variance criterion (highest variance jump in the dendrogram). For each of these subgroups, a conjoint analysis model was fitted on the data with the four qualitative factors $(\mathrm{C} 1, \mathrm{C} 2, \mathrm{C} 3, \mathrm{C} 4)$. The results of the conjoint analysis for each subgroup are given in Table 5. The part-worth utilities of the factor levels for the significant factors indicate if a level reinforces the response (positive value) or inhibits the response (negative value). The values of the part-worth for the not-significant components are not reported because they are considered as not relevant to explain the variance of the ratings.

Table 5. Results of the conjoint analysis model for the subgroups of users

\begin{tabular}{c|l|l|l|l}
\hline \multicolumn{5}{c}{ Pleasantness $Y_{1}$} \\
\hline & factor & p-value & \multicolumn{2}{c}{ Part-worth utilities } \\
\hline \multirow{4}{*}{ G1 } & C1 & n.s. & $/$ & $/$ \\
& C2 & n.s. & $/$ & $/$ \\
& C3 & $0.8 \%$ & Broad $=-9.4$ & Narrow $=+9.4$ \\
& C4 & n.s. & $/$ & $/$ \\
\hline \multirow{5}{*}{ G2 } & C1 & $3.5 \%$ & Yes $=+3.5$ & No $=-3.5$ \\
& C2 & n.s. & $/$ & $/$ \\
& C3 & n.s. & $/$ & $/$ \\
& C4 & n.s. & $/$ & $/$ \\
\hline \multirow{4}{*}{ G3 } & C1 & $0.3 \%$ & Yes $=-9.3$ & No $=+9.3$ \\
& C2 & n.s. & $/$ & $/$ \\
& C3 & n.s. & $/$ & $/$ \\
& C4 & $3.4 \%$ & Yes $=-6.4$ & No $=+6.4$ \\
\hline
\end{tabular}

\begin{tabular}{|c|c|c|c|c|c|}
\hline \multicolumn{6}{|c|}{ Appropriateness $Y_{2}$} \\
\hline & factor & p-value & \multicolumn{3}{|c|}{ Part-worth utilities } \\
\hline \multirow{5}{*}{ G4 } & $\mathrm{C} 1$ & $1.7 \%$ & Yes $=+2.5$ & & No $=-$ \\
\hline & & & & & 2.5 \\
\hline & $\mathrm{C} 2$ & n.s. & / & / & / \\
\hline & C3 & n.s. & / & / & / \\
\hline & $\mathrm{C} 4$ & $0.9 \%$ & Yes $=-4$ & & $\mathrm{No}=+4$ \\
\hline \multirow{5}{*}{ G5 } & $\mathrm{C} 1$ & $4.4 \%$ & Yes $=-5.3$ & & $\mathrm{No}=$ \\
\hline & & & & & +5.3 \\
\hline & $\mathrm{C} 2$ & n.s. & / & / & / \\
\hline & C3 & n.s. & / & / & / \\
\hline & $\mathrm{C} 4$ & n.s. & / & l & / \\
\hline \multirow{5}{*}{ G6 } & $\mathrm{C} 1$ & n.s. & / & I & 1 \\
\hline & $\mathrm{C} 2$ & $3.4 \%$ & Consonant $=$ & Dissonant & None $=$ \\
\hline & & & -4 & $=-2$ & +6 \\
\hline & C3 & n.s. & / & I & / \\
\hline & $\mathrm{C} 4$ & n.s. & / & l & / \\
\hline
\end{tabular}

For pleasantness, the results of the conjoint analysis exhibit three typical behaviors. The group G1 considers a 'narrow band noise' $(+9.4)$ as most 'pleasant' rather than a 'broad band noise'. G2 and G3 are opposite: G2 is attracted by the presence of a sound of an internal combustion engine $(+3.5)$, whereas G3 considers a sound without an internal combustion engine (+9.3) as most pleasant. Also, G3 does not appreciate modulation in the sound ( +6.4 for the level 'No').

For appropriateness, G4 and G5 are rather opposite. For G5, a sound with an internal combustion engine component is more appropriate, whereas G4 prefers the opposite, and is furthermore interested by the presence of modulation in the sound (+5.3). Group G6 finds the absence of musical chords more appropriate $(+6)$.

These results show a great diversity in the opinion about the sounds proposed and that no feature of the sound is mainly rejected or approved. This leaves a lot of degrees of freedom for the designer when designing sound and shows that a great variety of sounds can be candidates for the EV.

\section{CONCLUSIONS AND IMPLICATIONS}

In this paper, we explored the affective reaction of 34 novice users and six sound experts to 17 synthesized external sounds for electric cars. A qualitative analysis of words used when describing sounds and a quantitative analysis of the assessment according to pleasantness and appropriateness was conducted.

The main contributions of this paper concern the methodology used to analyze the qualitative and quantitative results, the differences in the perceptions of sounds between novice users and experts, and also recommendations concerning the design of sounds.

A majority of participants stated that it is a good idea or necessary to add sounds to electric cars. Most were already familiar with the safety issue from the media or quickly understood during the beginning of the experiment. There was, understandably, more enthusiasm or curiosity among the sound experts than there was among users. 
Should there be added sound for EVs? Experiments conducted in this study suggest that the idea of added sound is acceptable within the two samples. Added sound for EVs therefore seems to be a viable solution. The majority of both users $(57 \%)$ and experts (67\%) were in favor of adding sounds to electric vehicles and see the necessity, although with little enthusiasm.

In line with Lakoff and Johnson [41], our results show that subjects often associate what they perceive with something else that they are already familiar with. We recognize a traditional combustion engine because we have years of experience of what it sounds like. Even through with electric cars there are no pre-set standards, users, whether they are drivers, passengers or other people in the street, use the sound impression they know to categorize something as an electric car [42]. The most occurring answer of users to the question of what an EV should sound like was: "like a regular car" (see Figure 3). This result, in accordance with literature [25-26], is a sign of the importance of the psychological inertia and of the complexity of the design problem. On this topic, the opinions of sound experts varied: they made 'design-oriented' propositions, describing how they would design a sound for an EV. Differences between the groups suggest that we are facing challenges with briefing designers on how to design.

In describing perceived sounds, the coding of the words generated in categories showed that sound experts used a majority of composition-based adjectives, whereas users employed more character-related terms. Experts were focused on the technical aspects and were inclined to describe sounds in terms of their professional competences. Users expressed more easily connotations and feelings about the sounds.

Given that an assessment of artificial external sounds for electric vehicles is new, an agreed set of semantic attributes for evaluation of product character does not exist yet. Leaving the subjects to choose their own words to describe the sounds gives authentic attributes of participants' preferences to describe the sounds as they are. This is useful for designers in evaluating the intended product character and expected product experience. Instead of merely asking for pleasant - unpleasant, designers could use more specific words such as 'annoying' or 'unnerving' with novice users or 'synthetic' or 'monotonous' to qualify what unpleasant might mean.

Users and some sound experts pointed to low frequency and acceleration as 'good' aspects and high frequency and (fast) modulation as 'bad' aspects. But they were divided on the subject of how an electric vehicle should sound and it was not possible to draw a general trend.

The analysis of the quantitative ratings on pleasantness and appropriateness showed surprisingly a very weak agreement between the subjects. This weak agreement can be due to the fact that there are still few propositions on the market for sounds for EVs, so the possibilities are numerous. Another reason could be the absence of context to judge the sounds. It is likely that a sound for EVs played with a computer and a headphone, without visual contextualization, does not allow a sufficient immersion of the subject. The modeling of the users' responses to the design factors of the sounds with conjoint analysis gave different typologies in the group of users. But this analysis has to be confirmed with a more controlled design space according to the components of the sounds (design factors) to get useful feedbacks for taking design decisions.

Follow-up studies of the way expert sound designers and users characterize and describe electric vehicle sounds with larger samples of participants are needed to increase the power of analysis and confirm the trends indicated by our results. Avenues for future research include: Studies of preference vs. reaction times in real-time simulations to see if a preferred sound is also the safest. Further, in the interest of pedestrian safety studies of hearing-impaired pedestrians, reactions to new sound proposals as compared to existing car sounds should be undertaken.

\section{ACKNOWLEDGEMENTS}

The authors greatly appreciate the participation of the users and experts contributing to this study. The sounds were developed at IRCCyN, Ecole Centrale de Nantes. The research was carried out at the Technical University of Denmark.

\section{REFERENCES}

[1] Gillibrand, A., Suffield, I., Vinamata, X., Williams, R. and Brückmann, A., 2011. "An Initial Study to Develop Appropriate Warning Sound for a Luxury Vehicle Using an Exterior Sound Simulator". SAE International, 201101-1727.

[2] National Highway Traffic Safety Administration, 2009. Incidence of Pedestrian and Bicyclist Crashes by Hybrid Electric Passenger Vehicles [online], http://wwwnrd.nhtsa.dot.gov/Pubs/811204.pdf (date accessed November 15, 2012).

[3] Norman, D.A., 2007. The Design of Future Things. New York: Basic Books.

[4] Misdariis, N., Cera, A., Levallois, E., and Locqueteau, C., 2012. "Do electric cars have to make noise? An emblematic opportunity for designing sounds and soundscapes". Proceedings of Acoustics 2012, Nantes, France.

[5] Konet, H., Sato, M., Schiller, T., Christensen, A., Tabata, T., and Kanuma, T., 2011. "Development of Approaching Vehicle Sound for Pedestrians (VSP) for Quiet Electric Vehicles", SAE International, 2011-01-0928.

[6] SenseLab: Report, White Paper on External Warning Sounds for Electric Cars, May 2011, See also URL http://live.unece.org/fileadmin/DAM/trans/doc/2011/wp29 grb/QRTV-06-04e.pdf.

[7] Lyon, R.H., 2003. "Product Sound Quality from Perception to Design", Sound and vibration, vol. 37, no. 33, pp. 18-23.

[8] Crilly, N, Moultrie, J., and Clarkson, P J, 2004. "Seeing things: consumer response to the visual domain in product design", Design Studies. 25(6), 547-577.

[9] Crilly, N., Maier, A., and Clarkson, P. J., 2008. "Representing artefacts as media: Modelling the 
relationship between designer intent and consumer experience", International Journal of Design, 2(3), 15-27.

[10] Boatwright, P., and Cagan, J., 2010. "Built to Love: Creating Products that Captivate Customers", The Science of Product Emotions. San Francisco: Berrett Koehler Publishers Inc.

[11] Schifferstein, H. N. J., and Hekkert P. (eds), 2008. Product Experience, Amsterdam, The Netherlands, Elsevier.

[12] Siwiak, D., and James, F., 2009. "Designing Interior Audio Cues for Hybrid and Electric Vehicles", Proceedings of AES $36^{\text {th }}$ International Conference, Dearborn, Michigan, USA, 2009 June 2-4.

[13] Özcan, E., and Van Egmond, R., 2012. "Basic semantics of product sounds", International Journal of Design, vol. 6, no. 2, pp. 41-54.

[14] Clarkson, P. J., 2008. "Human capability and product design". In H. Schifferstein \& P. Hekkert (Eds.), Product Experience (pp. 165-198). Amsterdam: Elsevier.

[15] Van Egmond, R., 2008. "The Experience of Product Sounds", in Schifferstein, H., N., J., and Hekkert (eds) (2008) Product Experience, The Netherlands, Elsevier, pp. 69-89.

[16] Lemaitre, G., Susini, P., Winsberg, S., and Mc Adams, S., 2003. "Perceptively based design of new car horn sounds", Proceedings of the 2003 International Conference on Auditory Display, Boston, MA, USA, July 6-9.

[17] Roussarie, V., Richard, F., and Bezat, M.C., 2004. "Perceptive qualification of engine sound character; validation of auditory attributes using analysis-synthesis method". Proceedings of CFA/DAGA'2004.

[18] Cerrato, G., 2009. "Automotive Sound Quality Powertrain, Road and Wind Noise", Sound and Vibration, vol. 43, no. 4, pp. 16-24

[21] Yanagisawa, H., Kataoka, A., Murakami, T., Ohtomi, K., and Hosaka, R., 2009. "Extraction of Latent Emotional Factors by Analyzing Human Sensitivity towards Unexplored Design: Application to Product Sound Design", Proceedings of International Conference on Engineering Design, Stanford, CA, USA, August 24-27, ICED, vol. 7, pp. 13-24.

[22] Yanagisawa, H., Murakami, T., Noguchi, S., Ohtomi, K. and Hosaka, R., 2007. "Quantification Method of Diverse Kansei Quality for Emotional Design - Application of Product Sound Design", Proceedings of IDETC/CIE, Las Vegas, NV, USA, Sept. 4-7, ASME, pp. 1-10.

[23] Poirson, E., Petiot, J-F., and Richard, F., 2010. "A method for perceptual evaluation of products by naive subjects: Application to car engine sounds", International Journal of Industrial Ergonomics, vol. 40, no. 5, pp. 504-516.

[25] Wogalter M., Ornan R., Lim., and Chipley, R. , 2001. "On the risk of quiet vehicles to pedestrian and drivers", Proceedings of the Human Factors and Ergonomics Society, $45^{\text {th }}$ annual meeting, 2001.
[26] Nyeste, P., Wogalter, M., 2008. "On adding sound to quiet vehicles", Proceedings of the Human Factors and Ergonomics Society, $52^{\text {nd }}$ annual meeting.

[19] Petiot, J-F., and Yannou, B., 2004. "Measuring consumer perceptions for a better comprehension, specification and assessment of product semantics", International Journal of Industrial Ergonomics. Vol 33/6 pp 507-525.

[20] Hsu, S. H., Chuang, M. C., and Chang, C. C., 2000. “A Semantic Differential Study of Designers' and Users' Product Form Perception", International Journal of Industrial Ergonomics, vol. 25, no. 4, pp. 375-391.

[24] Edworthy, J., Hellier, E., and Hards, R., 1995. "The semantic associations of acoustic parameter commonly used in the design of auditory information and warning signals", Ergonomics, 38(11), 2341-2361.

[27] Ahmed, S., Wallace, K, M., and Blessing, L. S., 2003. "Understanding the differences between how novice and experienced designers approach design tasks". Research in Engineering Design. Vol. 14, Issue 1, pp 1-11.

[28] Williams, E. J., 1949. "Experimental designs balanced for the estimation of residual effects of treatments", Australian Journal of Scientific Research, Physical Sciences, vol. 2, no. 2, pp. 149-168.

[29] Ares, G., and Deliza, R., 2010. "Studying the influence of package shape and colour on consumer expectations of milk desserts using word association and conjoint analysis", Food Quality and Preference, 21, 930-937.

[30] Green, P. E., and Srinivasan, V., 1978. "Conjoint analysis in consumer research: Issues and outlook", Journal of Consumer Research, 5, 103-123.

[31] Piqueras-Fiszman, B., Velasco, C., Salgado-Montejo, A., and Spence, C., 2013. "Using combined eye tracking and word association in order to assess novel packaging solutions: A case study involving jam jars", Food Quality and Preference, 28(1), 328-338.

[32] Ajzen, I., and Fishbein, M., 1980. "Understanding attitudes and predicting behavior". Engelwood Cliffs, New Jersey: Prentice-Hall Inc.

[33] Cupchik, G., C. and Hilscher, M., C., 2008. "Holistic perspectives on the design of experience", in Schifferstein, H., N., J., and Hekkert (eds) (2008) Product Experience, The Netherlands, Elsevier, pp. 241-255.

[34] Strauss, A., and Corbin, J., 1998. "Basics of Qualitative Research". Techniques and Procedures for Developing Grounded Theory. London: Sage Publications.

[35] Dijksterhuis, G., 1995. "Assessing Panel Consonance", Food Quality and Preference, vol. 6, pp. 7-14.

[36] Green, P., Carroll, J., and Goldberg, S., 1981. "A general approach to product design optimization via conjoint analysis", Journal of Marketing, vol 43, pp 17-35.

[37] Hayashi, C., 1952.”On the prediction of phenomena from qualitative data from the mathematics-statistical point of view", Annals of the Institute of Statistical Mathematics, 3, pp.69-98. 
[38] Kuhfeld, W., 1997. "Efficient Experimental Designs Using Computerized Searches", Sawtooth Software Conference Proceedings.

[39] Koster, E.P., Couronne, T., Léon, F., Lévy, C., and Marcelino, A.S., 2002. "Repeatability in hedonic sensory measurement: a conceptual exploration". Food Quality and Preference 14, 165-176.
[40] Zwicker, E., and Fastl., H., 1990. "Psychoacoustics: Facts and models". Berlin, Germany: Springer.

[41] Lakoff, G., and Johnson, M., 1980. Metaphors We Live By, Chicago, IL, Chicago University Press.

[42] Smith, E. E., and Medin, D. L., 1981. Categories and concepts, Cambridge, MA, Harvard University Press.

\section{ANNEX A}

\section{DESCRIPTION OF THE 17 SYNTHESIZED SOUNDS}

\begin{tabular}{ccccc}
\hline Sound & $\begin{array}{c}\text { Component C1 } \\
\text { Motor component }\end{array}$ & $\begin{array}{c}\text { Component C2 } \\
\text { harmonic } \\
\text { component (chord) }\end{array}$ & $\begin{array}{c}\text { Component C3 } \\
\text { Noise } \\
\text { component }\end{array}$ & $\begin{array}{c}\text { Component C4 } \\
\text { Modulation } \\
\text { component }\end{array}$ \\
\hline S1 & yes (present) & dissonant & broad & yes \\
\hline S2 & yes & none (absent) & broad & no \\
\hline S3 & yes & none & broad & yes \\
\hline S4 & no (absent) & consonant & narrow & yes \\
\hline S5 & yes & dissonant & narrow & no \\
\hline S6 & yes & dissonant & narrow & yes \\
\hline S7 & no & none & broad & no \\
\hline S8 & no & none & broad & yes \\
\hline S9 & no & consonant & broad & no \\
\hline S10 & yes & none & broad & yes \\
\hline S11 & no & none & broad & yes \\
\hline S12 & no & dissonant & broad & no \\
\hline S13 & no & dissonant & broad & yes \\
\hline S14 & yes & none & broad & yes \\
\hline S15 & no & none & broad & yes \\
\hline S16 & yes & consonant & narrow & no \\
\hline S17 & yes & consonant & narrow & no \\
\hline & & & &
\end{tabular}

